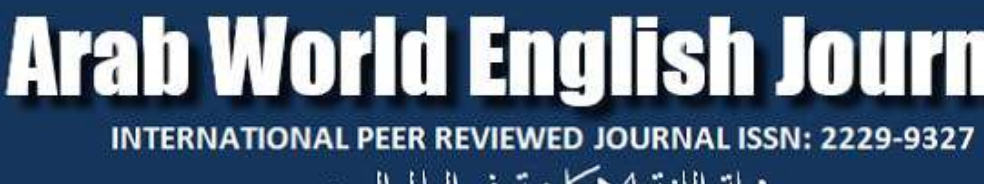 \\ بجاة اللفة الككيزية في العالم العربي
}

Arab World English Journal (AWEJ) Volume 9. Number 1. March 2018

DOI: https://dx.doi.org/10.24093/awej/vol9no1.17

Pp.233 - 255

\section{A Feature-Based Analysis of the Derivation of Word Order and Subject-Verb Agreement in Arabic Varieties}

\author{
Kamel Jouini \\ Faculty of Sciences and Theoretical Studies \\ Department of English Language and Translation \\ Saudi Electronic University, Jeddah, Saudi Arabia
}

\begin{abstract}
The derivation of common clause-type constructions like negation, interrogation (involving whelements) and declarativity (including sentences that involve topics) is a universal of sentence structure that involves a number of functional elements/items for the expression of negation, interrogation, or declarativity, cross-linguistically. However, as the present study on the derivation of syntactic word order (including subject-verb agreement configurations) in Arabic varieties shows, such functional elements/items can take a particular functional dimension within the functional domain they are part of. This study relies on sample examples from the literature on Arabic (the standard variety in particular, but also other varieties such as Tunisian Arabic and Moroccan Arabic - see Jouini, (2014) for typical sentences from these varieties) to demonstrate how functional elements can project as functional nodes or be merged as head or specifier (Spec) elements in the structure of sentences. In the inflectional domain of sentences - or Inflectional Phrase (IP) -, variation in subject-verb agreement configurations in Arabic rests on the premise that a Subject node variably projects giving rise to differing subject-verb agreement configurations. The same is true of the projection of the complementizer domain of sentences - or Complementizer Phrase (CP) - in Arabic, which splits into dedicated functional nodes in the standard variety of Arabic, but not in the modern spoken dialects. These differences in the projection of the IP-CP continuum establish functional relations upon which agreement and movement operations are derived and such notions as 'topic', 'subject' and 'focus' can be represented at the interface.
\end{abstract}

Key words: features, functional, Standard Arabic, Tunisian Arabic, subject-verb

Cite as: Jouini, K (2018). A Feature-Based Analysis of the Derivation of Word Order and Subject-Verb Agreement in Arabic Varieties. Arab World English Journal, 9 (1).

DOI: https://dx.doi.org/10.24093/awej/vol9no1.17 